\title{
ELISA validation approach for the detection of anti-Saccharomyces cerevisiae antibodies in patients treated with biopharmaceutical Heberprot- $\mathrm{P} \circledast$
}

\begin{abstract}
This work describes the validation of an enzyme-linked immunosorbent assay (ELISA) for detection of anti-Saccharomyces cerevisiae antibodies (ASCA) in diabetic patients with foot ulcers, after the treatment with Heberprot-P®. Validation followed regulatory guidelines of US FDA and European Medicine Agency. Minimum required dilution of samples and quality controls were defined using pools of sera from diabetic patients and from healthy donors. Parameters such as cut point, specificity, precision, selectivity, robustness and sample stability were analyzed. The repeatability and intermediate precision percent ranged between $7.93-10.61 \%$ and $7.93-11.43 \%$, respectively, indicating low intraand inter-assay variation. The specificity was proved by background noise suppression, reaching $100 \%$ of inhibition as strong criterion for the specificity of the immunoassay. The validated ELISA is a reliable tool for ASCA detection in human serum after the administration of Heberprot-P®, in order to find immunological reactions associated with latent contamination by host cell proteins from Saccharomyces cerevisiae.
\end{abstract}

Keywords: anti-Saccharomyces cerevisiae antibodies, diabetic patients, ELISA validation, serum samples
Volume 10 Issue 2 - 202I

\author{
Maylin Pérez-Bernal, ${ }^{\ddagger 1}$ Carlos Hernández, ${ }^{\ddagger 1}$ \\ Magali Delgado,' Mabel Izquierdo,' Ileana \\ Rosales, ${ }^{2}$ Enrique Pérez' \\ 'Research-Development Department, Center for Genetic \\ Engineering and Biotechnology of Sancti Spiritus, Cuba \\ ${ }^{2}$ Quality Control Direction, Center for Genetic Engineering and \\ Biotechnology, Cuba \\ ${ }^{\ddagger}$ Authors contributed equally
}

Correspondence: Maylin Pérez-Bernal, Center for Genetic Engineering and Biotechnology of Sancti Spiritus, Cuba, Tel+5355225340, Email maylin.perez@cigb.edu.cu

Received: December 20, 2020 | Published: March 08, 2021
Abbreviations: ELISA, enzyme-linked immunosorbent assay; ASCA, anti-Saccharomyces cerevisiae antibodies

\section{Introduction}

Saccharomyces cerevisiae is the most widely used yeast for recombinant protein production. This single-cell eukaryotic organism possesses the advantages of bacteria and eukaryotes: it is easy to culture, grows fast, can give high productivity, ${ }^{1}$ can ensure proper protein folding and post-translational modifications ${ }^{2}$ and it can secrete the product to the extracellular medium which simplifies purification. ${ }^{3}$ Moreover, as a generally recognized as safe organism, free of pyrogens also makes $S$. cerevisiae a favorable expression system for biopharmaceuticals. ${ }^{4}$ Even though $S$. cerevisiae is a good platform for biopharmaceuticals production, during the manufacture of such products, host cell-derived material will inevitably be introduced into the process stream. ${ }^{5}$ Such contamination can result in undesirable immunological reactions, by generating anti-Saccharomyces cerevisiae antibodies (ASCA) in patients that have been treated with the biopharmaceutical. ASCA including immunoglobulin IgG and $\operatorname{IgA}$, which appear to be specifically directed against mannose sequences of mannan present in the cell wall of $S$. cerevisiae. ${ }^{6}$ At present, ASCA is one of the most commonly used serologic antibody markers for diagnosis of inflammatory bowel diseases. ${ }^{6,7}$ In addition, $S$. cerevisiae is common yeast found in various foods; consequently ASCA can appear in healthy persons too. For that, it is very important to know the serum levels of ASCA in the patients, pre- and posttreatment with any biopharmaceutical obtained from $S$. cerevisiae expression system, in order to recognize the ASCA associated with the bio-product.

Enzyme-linked immunosorbent assay (ELISA) is frequently utilized for immunogenicity recognition. The current available ELISA methods for the detection of ASCA agree well but differ greatly in the interpretation of results. It is clear that cut points have been chosen for different purposes, lipemic and hemolytic samples should not be used or have been used with cautions, and the thermostability of the samples is not the same in different ASCA assays. ${ }^{8}$ In addition, commercial ELISA kits are expensive and not always readily available. Particularly for the clinical studies related with Heberprot-P ${ }^{\circ}$, a biopharmaceutical produced by $S$. cerevisiae, with direct effects on granulation and epithelialization of diabetic foot ulcers, it's still necessary the validation of an ELISA for the intended purpose of ASCA detection in human serum after the administration of this biopharmaceutical, as a reliable method to detect immunological reactions associated with latent contamination by host cell proteins from yeast. The aim of this work was to validate an ELISA for the detection of ASCA in serum from diabetic patients with foot ulcers after the treatment with Heberprot-P ${ }^{\circledR}$. Validation parameters suggested by regulatory guidelines of US Food and Drug Administration ${ }^{9,10}$ and European Medicine Agency ${ }^{11}$ were assessed. As the percent of inhibition to validate the specificity has not been specified for guidelines, this work included a method to eliminate the possible background noise that can affect the percent of inhibition, in order to consider a percent close to $100 \%$ as a strong criterion that supports the specificity of the immunoassay.

\section{Materials and methods}

\section{Origin of human serum}

Individual human serum samples obtained from 30 healthy donors and pools of sera from 30 diabetic patients with foot ulcer, before and after the treatment with Heberprot-P ${ }^{\circledR}$, were used for the validation protocol. All sera were stored at $-20^{\circ} \mathrm{C}$ until use.

\section{Enzyme-linked immunosorbent assay}

Polystyrene 96-well microtiter plates (Costar ${ }^{\mathrm{TM}}$ High Binding 3590 ), were coated with $10 \mu \mathrm{g} / \mathrm{mL}$ of the antigen (Reference Material 
of contaminants from $S$. cerevisiae as host cell for Recombinant Epidermal Growth Factor, lot 03SFD16002N, CIGB, Havana, Cuba) in $100 \mu \mathrm{L} /$ well coating buffer (phosphate-buffered saline, $\mathrm{pH}$ 7.2) and incubated $1 \mathrm{~h}$ at $37^{\circ} \mathrm{C}$. Wells were washed four times with $350 \mu \mathrm{L} /$ well washing buffer $(0.292 \mathrm{M}$ Tris (hydroxymethyl) aminomethane, $0.228 \mathrm{M} \mathrm{HCl}(37 \%), 3.75 \mathrm{M} \mathrm{NaCl}$ and $1.25 \%$ Tween-20, $\mathrm{pH} 8.0$ ) and blocked with $350 \mu \mathrm{L} /$ well blocking buffer (washing buffer with $1 \%$ nonfat dried milk powder, $\mathrm{pH} 8.0) 1 \mathrm{~h}$ at $37^{\circ} \mathrm{C}$. The plate was washed once with washing buffer and $100 \mu \mathrm{L}$ of quality controls and serum samples diluted with blocking buffer were added to wells and incubated $1 \mathrm{~h}$ at $37^{\circ} \mathrm{C}$. Plates were washed four times and $100 \mu \mathrm{L}$ antihuman polyvalent alkaline-phosphatase-conjugated (Sigma; 1:5000 in blocking buffer) was added to each well and incubated $\left(1 \mathrm{~h}, 22-25^{\circ} \mathrm{C}\right)$. After four washes, $100 \mu \mathrm{L} /$ well $1.0 \mathrm{mg} / \mathrm{mL}$ p-nitrophenyl phosphate, 1.0 $\mathrm{M}$ di-ethanolamine and $0.5 \mathrm{mM} \mathrm{MgCl}, \mathrm{pH} 9.8$, was added and incubated $30 \mathrm{~min}$ at $28^{\circ} \mathrm{C}$ in the dark. Color development was stopped by adding $100 \mu \mathrm{L} /$ well of $0.1 \mathrm{M}$ di-sodium EDTA. Absorbance was measured at $405 \mathrm{~nm}\left(\mathrm{~A}_{405 \mathrm{~mm}}\right)$ in a microplate reader (Labsystems Multiskan ${ }^{\circledR}$ Plus, Finland)

\section{Minimum required dilution (MRD)}

The MRD was determined as the minimum dilution that can maximize the difference between the $\mathrm{A}_{405 \mathrm{~nm}}$ of a pool of sera from diabetic patients with foot ulcer before treatment with Heberprot- $\mathrm{P}{ }^{\circledR}$, and the $\mathrm{A}_{405 \mathrm{~nm}}$ of a pool of sera from healthy donors, with the minimum photometric error $\left(\mathrm{A}_{405 \mathrm{~nm}}\right.$ close to 0.432$)$. Both pools of sera were twofold serial diluted, from 1:1600 to 1:100. Each dilution point was duplicated in the ELISA plate.

\section{Quality controls}

Three quality controls (QCs) were prepared with a pool of sera from healthy donors diluted with blocking buffer as follows:

Negative control (NC): Pool of sera diluted at MRD and preincubated with $100 \mu \mathrm{g} / \mathrm{mL}$ of the antigen used for coating, $1 \mathrm{~h}$ at (22$25)^{\circ} \mathrm{C}$.

\section{High Positive Control (HPC): Pool of sera diluted 1:20}

Low Positive Control (LPC): Pool of sera diluted 1:75.

Once the QCs were prepared, the next step was to determine the range of acceptable values for them. QCs were studied in triplicates by two analysts in six independent runs, over three different days each one. Outliers were identified by the Box Plot method and removed from the runs. The NC complied the acceptance criterium if it not above the one-sided confidence interval (99\%) determined by the formula: mean $\left(\log \mathrm{A}_{405 \mathrm{~nm}}\right)+\mathrm{t}(0.01 ; \mathrm{DF}) \times \mathrm{SD}$ (standard deviation). HPC and LPC should be in their two-sided confidence intervals (99\%), calculated by using the ratio $\mathrm{PC} / \mathrm{NC}$, established between $\mathrm{A}_{405 \mathrm{~nm}}$ of corresponding positive control and $\mathrm{A}_{405 \mathrm{~nm}}$ of negative control. The intervals were determined by the formula: mean $(\log \mathrm{PC} / \mathrm{NC}) \pm \mathrm{t}(0.01 ; \mathrm{DF}) \mathrm{x} \mathrm{SD}$.

\section{Cut-point}

The cut-point (CP) was defined by analyzing 34 individual human serum samples from diabetic patients with foot ulcer before treatment with Heberprot-P®. Samples were diluted at MRD and studied in duplicates by two analysts in six independent runs, over three different days each one. A parametric approach (one sided, 99\% confidence level) was selected to calculate the cut-point. The variable was the $\log$-transformed $\mathrm{S} / \mathrm{N}$. The ratio $\mathrm{S} / \mathrm{N}$ (signal/noise) was established between the $A_{405 \mathrm{~nm}}$ from serum samples and the $\mathrm{A}_{405 \mathrm{~nm}}$ from negative control. Outliers were identified by the Box Plot method and removed from the runs. Data normality was analyzed using the Shapiro-Wilk test and the variance homogeneity was evaluated by the Levene test. A single factor ANOVA was applied to evaluate if the means of the runs were significantly different or not. All hypothesis tests were achieved with $\alpha=0.05$. SD was estimated by performing a variance component analysis using restricted maximum likelihood method within the framework of a nested ANOVA. The cut point was calculated by the formula:

$$
\log P C=\text { media }(\log S / N)+2.33 \times S D,
$$

where 2.33 is the $99^{\text {th }}$ percentile of the normal distribution

\section{Specificity}

The evaluation of specificity was performed by an inhibition assay. A pool of sera from 20 diabetic patients with foot ulcer after the treatment with Heberprot-P ${ }^{\circledR}$, diluted at MRD, was pre-incubated with $100 \mu \mathrm{g} / \mathrm{mL}$ of the antigen during $1 \mathrm{~h}$ at $(22-25){ }^{\circ} \mathrm{C}$. The noninhibited sample had PBS instead of the antigen. The inhibited and non-inhibited specimens were placed in triplicates in the ELISA plates, using two variants with the aim of background noise suppression: plate coated with the antigen and blocked as described before, and plate without coating but blocked. The percent of inhibition (\%I) was calculated as follows:

$\% \mathrm{I}=100-\left[\left(\mathrm{A}_{405 \mathrm{~nm}}\right.\right.$ inhibited sample $) /\left(\mathrm{A}_{405 \mathrm{~nm}}\right.$ non-inhibited sample)] x 100

ELISA was considered specific if the mean of the percent of inhibition was close to $100 \%$.

\section{Precision}

Precision was evaluated by repeating the assay in six analytical runs by two analysts, using as samples the negative control and three pools of sera with high, medium and low concentration of ASCA, obtained from healthy donors. The samples with high and medium concentration of ASCA coincided with the HPC and LPC, respectively. But the sample with low concentration of ASCA was prepared by diluting the pool of healthy donors 1:500 with blocking buffer. Each sample was evaluated in triplicates. The ratio $\mathrm{S} / \mathrm{N}$ in logarithmic scale was used as dependent variable. SD was estimated by a variance component analysis using restricted maximum likelihood method within the framework of a nested ANOVA. Intra- and inter-assays precision, expressed as percent of coefficient of variation $(\% \mathrm{CV})$ at each concentration level, should not exceed $20 \%$, and was calculated according to the formulas:

$$
\begin{aligned}
& \% \text { CVintra }- \text { assay }=[\sqrt{10 \wedge}(\text { variance of error })-1] x 100 \\
& \% \text { CVinter }- \text { assays }=\left[\sqrt{ } 10^{\wedge}(\sqrt{ } \text { V variance components })-1\right] x 100
\end{aligned}
$$

\section{Selectivity}

Selectivity was evaluated by testing two types of samples: eight individual hemolytic sera and eight individual lipemic sera, diluted at MRD. Serial two-fold dilutions, from 1:20 to 1:2560, were performed in duplicates for each individual serum, for the HPC and for each serum spiked with the HPC. Absorbance of individual sera, HPC and spiked sera, were estimated at MRD by plotting $\mathrm{A}_{405 \mathrm{~nm}}$ versus dilution factor. The percent of recovery $(\% \mathrm{R})$ was calculated by the formula: 


$$
\begin{gathered}
A_{405 n m}(\text { individual serum sample spiked with } H P C) \\
\% R=-----------------------------x 100 \\
A_{405 n m}(\text { individual serum sample })+A_{405 n m}(H P C)
\end{gathered}
$$

Sample was considered not interfering if the percent of recovery was between 80 and $120 \%$.

\section{Robustness}

There were made small changes in critical parameters of the ELISA procedure: variation in \pm 5 min the plate incubation times for antigen coating, for QCs and for anti-human polyvalent alkaline-phosphataseconjugated; variation in $\pm 0.2 \mathrm{mg} / \mathrm{mL}$ the substrate concentration. All treatments were assayed by triplicates. The robustness was proved by the fulfilling of the QCs confidence intervals

\section{Stability of samples and quality controls}

Since the QCs and samples are of the same species, the stability of both was proved by the fulfilling of the QCs confidence intervals $(99 \%)$. Short-term stability (6 hours at room temperature (20-25) ${ }^{\circ} \mathrm{C}$ and 6 days at $(2-8){ }^{\circ} \mathrm{C}$ ) and freeze-thaw stability (six freezethaw cycles), were tested using the QCs acceptance limits. For the evaluation of freeze-thaw stability, aliquots of each QC were thawed unassisted at room temperature. When completely thawed, the aliquots were refrozen at $-20^{\circ} \mathrm{C}$ for at least 20 hours. This freeze-thaw cycle was repeated five more times.

\section{Statistical analysis}

Statistical analyses were performed using Microsoft ${ }^{\circledR}$ Office Excel (2010) and the Statistical Package for Social Science 15.0. Curve fitting were achieved using Sigma Plot 12

\section{Results and discussion}

\section{Minimum required dilution}

The MRD is the dilution that yields a signal close to the signal of non-specific binding of assay diluent. ${ }^{12}$ High incidences of preexisting ASCA are commonly found in healthy people sera, and it is difficult to obtain a suitable number of true negative samples and consequently to find an MRD ranged from 1:5 to 1:100 as recommended by FDA. ${ }^{9}$ Taking into account this inconvenience, in the present work the MRD was determined as the minimum dilution that maximizes the difference, with the minimal photometric error, between the $\mathrm{A}_{405 \mathrm{~nm}}$ of a pool of sera from diabetic patients, with foot ulcer before treatment with Heberprot-P ${ }^{\circledR}$, and the $A_{405 \mathrm{~mm}}$ of a pool of sera from healthy donors. Five 1:2 serial dilutions were performed in both pools of sera. Dilution factor versus $\mathrm{A}_{405 \mathrm{~nm}}$ were plotted using a logistic regression of five parameters (Figure 1). In the Figure 1A, a dilution factor of 500 was obtained by interpolating $\mathrm{A}_{405}=0.432$ as the minimal photometric error. Then, this dilution factor was interpolated in the curve corresponding to the pool of healthy donors and it was obtained $\mathrm{A}_{405 \mathrm{~nm}}=0.077$. The ratio of both $\mathrm{A}_{405 \mathrm{~nm}}$ values was 5.6. Subsequently, this ratio was calculated using the $A_{405 \mathrm{~nm}}$ of both pools obtained with 100 as dilution factor and the result was 4.1, a value 1.4 fold-low than the ratio obtained with 500 as dilution factor. This result proved the suitability of the use of 1:500 as MRD, because it maximized the difference between the $\mathrm{A}_{405 \mathrm{~nm}}$ of a pool of sera from diabetic patients with foot ulcer before treatment with Heberprot- $\mathrm{P} \AA$, the target population, and the $\mathrm{A}_{405 \mathrm{~nm}}$ of a pool of sera from healthy donors.
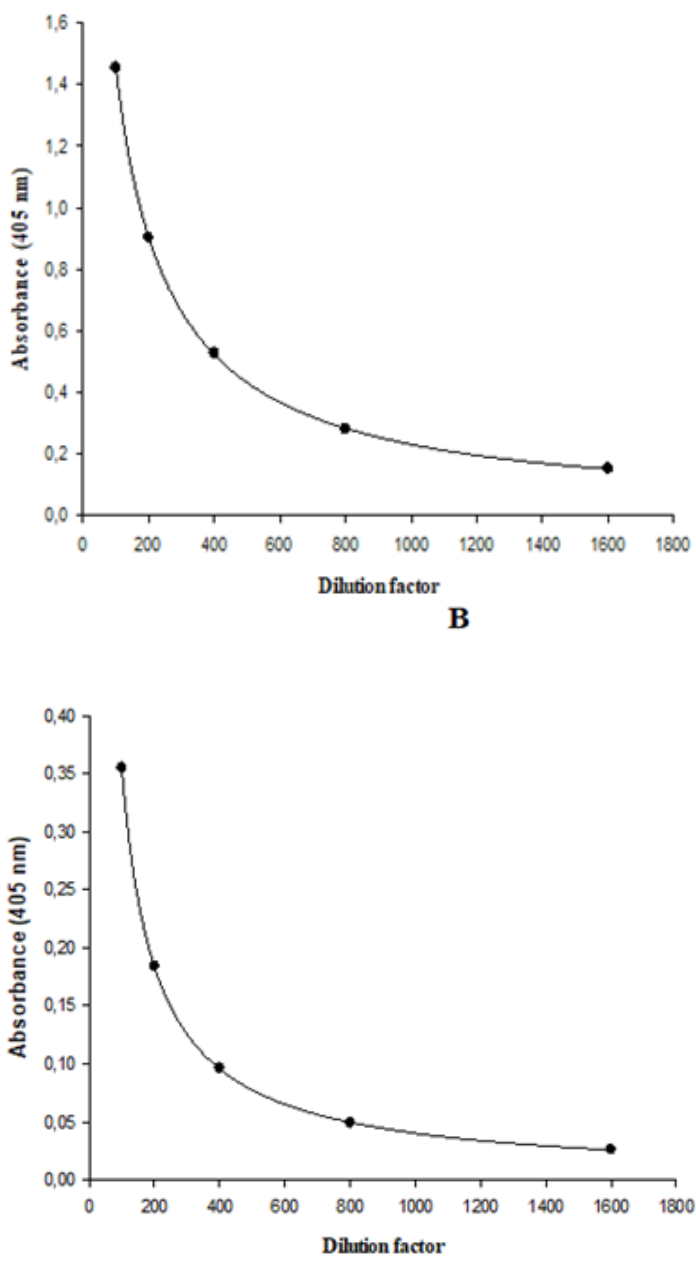

Figure I Representation of logistic regression of five parameters for I:2 serial dilutions of the pool of sera from (A) diabetic patients with foot ulcer

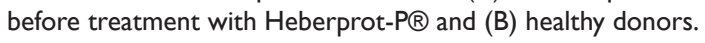

\section{Quality controls confidence intervals}

As $S$. cerevisiae is common yeast found in various foods, ASCA can appear in healthy persons and is very difficult to find a serum without ASCA as negative control. As novelty for this work is the use of a negative control, prepared with a pool of sera diluted with blocking buffer at MRD and pre-incubated with $100 \mu \mathrm{g} / \mathrm{mL}$ of the antigen used for plate coating. The purpose of obtaining 36 data points by running each QC was to quantify normal variation and establish the one-sided confidence interval (99\%) for negative QC and the two-sided confidence intervals (99\%) for low and high positive QCs (Table 1). Three outliers were identified by the Box Plot method and were not included when calculating the confidence intervals. These intervals will be used to monitor the performance and acceptability of the ELISA during subsequent validation parameters and clinical assays. 
Table I Definition of the confidence intervals for the quality controls of the ELISA

\begin{tabular}{|c|c|c|c|c|}
\hline Quality & & & & One-sided confidence interval (99\%) \\
\hline Control & $\log ($ mean A405nm) & t (0.0I; I 0 DF) & SD & \\
\hline \multirow[t]{3}{*}{ NC } & -1.669 & 2.764 & 0.052 & 0.03 \\
\hline & & & & Two-sided confidence interval ( $99 \%)$ \\
\hline & $\log ($ mean PC/NC) & t (0.0I; I I DF) & SD & \\
\hline LPC & 1.537 & 3.106 & 0.056 & low: 23.12; high: 51.22 \\
\hline HPC & 1.88 & 3.106 & 0.052 & low: 52.24; high: I 10.21 \\
\hline
\end{tabular}

NC, negative control; LPC, low positive control; HPC, high positive control

$A_{405 n \mathrm{n}}$, Absorbance measured at $405 \mathrm{~nm}$; SD, Standard deviation; DF, degrees of freedom

$\mathrm{PC} / \mathrm{NC}$, ratio $\mathrm{A}_{405 \mathrm{~nm}}$ of positive control/ $\mathrm{A}_{405 \mathrm{~nm}}$ of negative control

One-sided confidence interval (99\%) for NC, mean (logA405nm) + t (0.0I; DF) x SD

Two-sided confidence interval (99\%) for LPC and HPC: mean (log PC/NC) \pm t $(0.01$; DF) $\times$ SD

\section{Cut-point}

In determining the $\mathrm{CP}$, is important to use test samples as similar as possible to the study samples. ${ }^{12}$ In the present assay, the CP was established by analyzing individual human serum samples from diabetic patients with foot ulcer before treatment with Heberprot-P ${ }^{\circledR}$, which are the study samples. The logarithm of the ratio $\mathrm{S} / \mathrm{N}$ was used as variable; 42 outliers obtained from five consecutive iterations were removed, and 162 values of $\mathrm{S} / \mathrm{N}$ remained for the determination of CP. The Shapiro-Wilk test ( $\mathrm{p} \geq 0.05$ ) demonstrated the normality of $\log \mathrm{S} / \mathrm{N}$ data. The $\mathrm{p}$-value from the Levene test was 0.95 , suggesting that the variances across assay runs were not significantly different at alpha $=0.05$ significance level. The single factor ANOVA demonstrated that means were also not significantly different $(\mathrm{p}=0.97)$ between runs. These results sustained the use of a fixed cut point for the assay. The media of log-transformed $\mathrm{S} / \mathrm{N}$ was 0.45 , and the standard deviation was calculated by restricted maximum likelihood method within the framework of a nested ANOVA. The components of variance were the 'analyst' and 'day' factors, but the factor 'error' was exclusively responsible for variance (Table 2). Substituting the mean value and the standard deviation into the formula $\log \mathrm{PC}=$ media $(\log \mathrm{S} / \mathrm{N})+$ $2.33 \times \mathrm{SD}$, a cut point of 15.57 was obtained.

Table 2 Estimation of standard deviation of log-transformed S/N by restricted maximum likelihood method within the framework of a nested ANOVA

\begin{tabular}{ll}
\hline Variance components & Estimation \\
\hline Analyst & 0.00 \\
Day (Analyst) & 0.00 \\
Error & 0.10 \\
Total Variance & 0.10 \\
Standard Deviation & 0.32
\end{tabular}

$\mathrm{S} / \mathrm{N}$, Ratio $\left(\mathrm{A}_{405 \mathrm{~nm}}\right.$ of each sample $) /\left(\mathrm{A}_{405 \mathrm{~nm}}\right.$ of negative control)

\section{Specificity}

The specificity of an antibody refers to its ability to bind to the antigen of interest, but not to other assay components such as surfaces or reagents. ${ }^{9}$ A straightforward approach to addressing specificity is to demonstrate that binding can be blocked by soluble antigen in the inhibition step, as performed in the present study using a pool of sera from diabetic with foot ulcer before the treatment with Heberprot-P ${ }^{\circledR}$. The possible background noise that can affect the percent of inhibition, was assessed by placing the inhibited and non-inhibited specimens in the ELISA plate coated with the antigen and blocked, and in the plate without coating but blocked. It was demonstrated that the method exhibited background noise affecting the specificity, possibly due to the blocking reagent, ${ }^{13}$ in which the non-specific inhibition percentage was $3.23 \%$ (Table 3). Background noise was suppressed by using the difference of signal obtained with coated and non-coated plates, to determine the percent of inhibition, which was close to $100 \%$ (Table 3). Taking into account the background suppression, the ELISA was considered specific.

Table 3 Evaluation of the specificity of the ELISA

\begin{tabular}{llll}
\hline & $\begin{array}{l}\text { Coated } \\
\text { plate }\end{array}$ & $\begin{array}{l}\text { Non-coated } \\
\text { plate }\end{array}$ & $\begin{array}{l}\text { Difference } \\
\text { coated - } \\
\text { Non-coated }\end{array}$ \\
\hline $\begin{array}{l}\text { A405nm inhibited } \\
\text { sample }\end{array}$ & 0.029 & 0.03 & -0.001 \\
$\begin{array}{l}\text { A405nm non- } \\
\text { inhibited sample }\end{array}$ & 0.287 & 0.031 & 0.256 \\
$\%$ Inhibition & 89.9 & 3.23 & 100.39
\end{tabular}

Values of absorbance $\left(A_{405 \mathrm{~nm}}\right)$ represent the mean of three replications. \%Inhibition $=100-\left[\left(A_{405 \mathrm{~nm}}\right.\right.$ inhibited sample $) /\left(A_{405 \mathrm{~nm}}\right.$ non-inhibited sample $\left.)\right]$ $\times 100$

Some discrepancies are marked when assessing specificity for ligand binding assays. In FDA guidelines ${ }^{9,10}$ chapter of specificity is not given. Description related to specificity is contained in chapter of selectivity briefly and not in detail. The distinctions between the agencies concern sample concentrations, type of matrix, and concentration of interfering molecules,${ }^{14}$ but the acceptance criterion for the percent of inhibition has been not specified for regulatory guidelines. The use of subjective criteria, such as $\geq 50 \%$ inhibition of signal, is discouraged..$^{15}$ We consider that a percent of inhibition close to $100 \%$ is a strong criterion that supports the specificity of the immunoassay. To achieve this, it is necessary to guarantee the optimal conditions for the antigen-antibody reaction during the inhibition step, and to eliminate background noise as has been done in the present work.

\section{Precision}

The intra-assay precision (repeatability) expresses the precision under the same operating conditions over a short interval of time. The 
inter-assay precision (intermediate precision) validation verifies that in the same laboratory the method will provide the same results once the development phase is over..$^{13}$ For our experimental conditions, the repeatability and intermediate $\mathrm{CV}$ precision percent ranged between $7.93-10.61 \%$ and $7.93-11.43 \%$, respectively (Table 4) indicating low intra- and inter-assay variation. These results indicated that the ELISA fulfills the specifications for precision, in accordance with guidelines for the validation of analytical procedures. ${ }^{9,11}$ The precision was sufficient to allow the direct comparison of samples processed by two analysts at different days.

Table 4 Determination of precision intra- and inter-assays in six independent runs

\begin{tabular}{llllll}
\hline \multicolumn{3}{c}{ Variance Components } & \multicolumn{3}{c}{ CV (\%) } \\
\hline Sample & Analyst & Day (Analyst) & Error & Intra-assay & Inter-assays \\
\hline NC & 0.000650 & 0.000131 & 0.004859 & 10.61 & 11.43 \\
LCS & 0.000000 & 0.000595 & 0.00317 & 8.56 & 9.33 \\
MCS & 0.000000 & 0.000000 & 0.003093 & 8.45 & 8.45 \\
HCS & 0.000000 & 0.000000 & 0.002724 & 7.93 & 7.93
\end{tabular}

NC, negative control; LCS, sample with low ASCA concentration; MCS, sample with medium ASCA concentration; HCS, sample with high ASCA concentration $\mathrm{S} / \mathrm{N}$ : Ratio $\left(\mathrm{A}_{405 \mathrm{~nm}}\right.$ of each sample $) /\left(\mathrm{A}_{405 \mathrm{~nm}}\right.$ of $\left.\mathrm{NC}\right)$

$\% C V$ intra-assay $=\left[\sqrt{ } 10^{\wedge}\right.$ (variance of error $\left.)-I\right] \times 100$

$\% \mathrm{CV}$ inter-assays $=\left[\sqrt{ } 10^{\wedge}\left(\sqrt{ } \sum\right.\right.$ variance components $\left.)-I\right] \times 100$

\section{Selectivity}

Selectivity is the ability of an analytical method to detect and differentiate the analyte in the presence of other components in the sample. In the present study, selectivity was assessed using two kinds of samples: hemolytic and lipemic sera, since the most common nonspecific interferences in ELISA assays are due to hemolysis and lipemia. ${ }^{16}$ According to the $\mathrm{FDA}^{9}$ and $\mathrm{EMA}^{11}$ guidelines, individual matrices for human should be spiked with a standard at or near the low limit of quantification to evaluate selectivity. In our experiments, a standard with known concentration of ASCA did not exist and it was necessary to apply a different method to evaluate the recovery in possible interfering samples. The method was based on serial dilutions

of three types of specimens: individual serum samples (lipemic or hemolytic), the HPC and the mixture of both. Data of $\mathrm{A}_{405 \mathrm{~mm}}$ obtained from each specimen were plotted versus dilution factor using a logistic regression of five parameters. The value of $\mathrm{A}_{405 \mathrm{~mm}}$ at MRD was obtained by interpolation and it was used for calculating the percent of recovery in each probable interfering sample. The percent of recovery for each individual serum sample was in the acceptance range (Table 5), and it signified that the absorbance of the individual serum spiked with HPC was practically equivalent to the sum of the absorbances of individual serum and HPC, evaluated by separate. Thus, hemolysis and lipemia did not interfere in the capacity of the ELISA to detect the ASCA in serum samples.

Table 5 Evaluation of the selectivity of the ELISA by recovery estimation

\begin{tabular}{lllll}
\hline \multicolumn{5}{l}{ A405nm obtained by interpolation at MRD } \\
\hline $\begin{array}{l}\text { Code for individual } \\
\text { serum samples }\end{array}$ & $\begin{array}{l}\text { Individual serum } \\
\text { sample }\end{array}$ & HPC & $\begin{array}{l}\text { Serum samples } \\
\text { spiked with HPC }\end{array}$ & $\% R$ \\
\hline HI & 0.136 & 0.149 & 0.261 & 91.67 \\
H2 & 0.158 & 0.196 & 0.321 & 90.5 \\
H3 & 0.151 & 0.187 & 0.306 & 90.47 \\
H4 & 0.146 & 0.16 & 0.278 & 90.6 \\
H5 & 0.191 & 0.208 & 0.349 & 87.42 \\
H6 & 0.17 & 0.21 & 0.342 & 89.83 \\
H7 & 0.142 & 0.178 & 0.295 & 92.15 \\
H8 & 0.162 & 0.2 & 0.327 & 90.49 \\
LI & 0.017 & 0.149 & 0.142 & 85.94 \\
L2 & 0.173 & 0.196 & 0.329 & 88.69 \\
L3 & 0.165 & 0.187 & 0.312 & 88.7 \\
L4 & 0.022 & 0.16 & 0.154 & 84.34 \\
L5 & 0.042 & 0.208 & 0.2 & 80.02 \\
\hline
\end{tabular}


Table Continued.

\begin{tabular}{lllll}
\hline \multicolumn{5}{l}{ A405nm obtained by interpolation at MRD } \\
\hline $\begin{array}{l}\text { Code for individual } \\
\text { serum samples }\end{array}$ & $\begin{array}{l}\text { Individual serum } \\
\text { sample }\end{array}$ & HPC & $\begin{array}{l}\text { Serum samples } \\
\text { spiked with HPC }\end{array}$ & \%R \\
\hline L6 & 0.186 & 0.21 & 0.348 & 87.93 \\
L7 & 0.156 & 0.178 & 0.3 & 90.04 \\
L8 & 0.176 & 0.2 & 0.333 & 88.56 \\
\hline
\end{tabular}

$\mathrm{HI}$ to H8, eight individual hemolytic serum samples; LI to L8, eight individual lipemic serum samples; HPC, high positive control; \%R, percent of recovery; MRD, minimal required dilution $(1: 500)$

$$
\begin{gathered}
A_{405 \mathrm{~nm}}(\text { individual serum sample spiked with HPC }) \\
\% R=-----------------------------x 100 \\
A_{405 \mathrm{~nm}}(\text { individual serum sample })+A_{405 \mathrm{~nm}}(\mathrm{HPC})
\end{gathered}
$$

\section{Robustness}

The complexity of bioassays makes them particularly susceptible to variations in assay conditions, and it is essential to evaluate the robustness, assessed by the capacity of the assay to remain unaffected by small but deliberate variations in method parameters. For example, changes in temperature, incubation times, reagent lots and buffer characteristics. ${ }^{9,11}$ The robustness of this assay was evaluated by varying the incubation time in $\pm 5 \mathrm{~min}$ for antigen coating, QCs and anti-human polyvalent alkaline-phosphatase-conjugated; and by changing the substrate concentration in $\pm 0.2 \mathrm{mg} / \mathrm{mL}$. All these variations did not alter the acceptability of QCs; the runs were accepted as "in-control" (Figure 2). This was a confirmation of the capability of the ELISA to remain unaffected by small deliberate changes in method parameters, and it provided an indication of its reliability during normal run conditions.
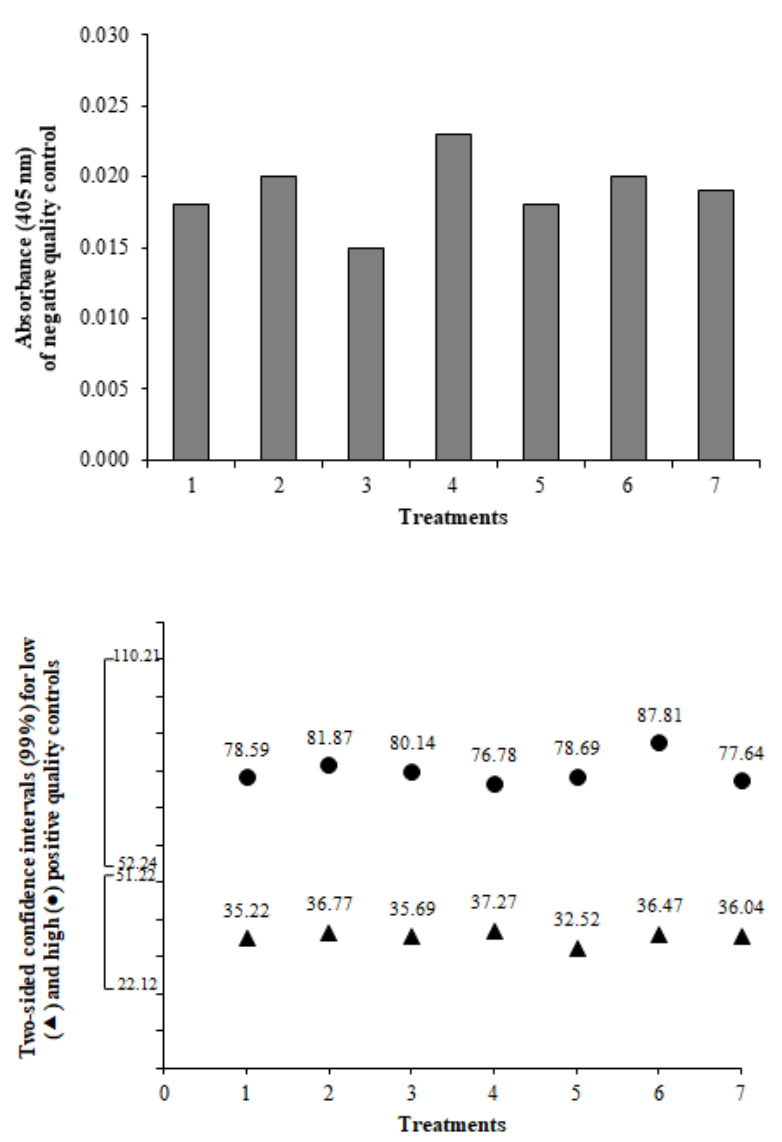

Figure 2 Evaluation of the robustness of the ELISA (treatments I to 4) and the stability of serum samples (treatments 5, 6 and 7) by the fulfilling of (A) negative and (B) positive quality controls confidence intervals. Data represents the mean of three replications. Treatments: $(I)$ variation in -5 min the plate incubation times for antigen coating, for quality controls and for anti-human polyvalent alkaline-phosphatase-conjugated; $(2)$ variation in +5 min the plate incubation times for antigen coating, for quality controls and for anti-human polyvalent alkaline-phosphatase-conjugated; (3) variation in $-0.2 \mathrm{mg} / \mathrm{mL}$ the substrate concentration; (4) variation in $+0.2 \mathrm{mg} / \mathrm{mL}$ the substrate concentration; (5) 6 hours at room temperature (20-25) ${ }^{\circ} \mathrm{C}$; (6) 6 days at $(2-8)^{\circ} \mathrm{C}$; (7) 6 freeze-thaw cycles. Confidence intervals (99\%) for quality controls: $\mathrm{A}_{405 \mathrm{~nm}} \mathrm{NC} \leq 0.03022 .12 \leq \mathrm{LPC} / \mathrm{NC} \leq 5 \mathrm{I} .2252 .24 \leq \mathrm{HPC} / \mathrm{NC} \leq \mathrm{II} 0.21$.

Citation: Pérez-Bernal M, Hernández C, Delgado M, et al. ELISA validation approach for the detection of anti-Saccharomyces cerevisiae antibodies in patients treated with biopharmaceutical Heberprot-P®. J Anal Pharm Res. 2021;10(2):50-56. DOI: I0.I5406/japlr.202I.10.00365 


\section{Stability of samples and quality controls}

Frozen serum material is usually stable for a long time, but its stability should be monitored over time because the assay lifetime can be very long. ${ }^{5}$ Determination of the number of freeze/thaw cycles, storage times and temperatures should be based on the expected handling and storage of the serum samples. If QCs have been prepared in the same matrix as the study samples, the use of QCs with high and low levels of antibody evaluates the stability of samples. ${ }^{11}$ In the present study, the negative and positive quality controls were applied for the stability assessment. For the evaluation of the stability, QCs were submitted at temperature conditions commonly used for the processing and storing of samples during the ELISA. The results of stability assessments confirmed that QCs were stable in all tested conditions, since all the measures were into the confidence intervals (99\%) (Figure 2). The stability of QCs with high and low concentration of ASCA reflected the stability of the study samples, because the QCs and samples are of the same species.

\section{Conclusion}

An ELISA for the detection of ASCA in patients treated with Heberprot- $\mathrm{P} \AA$ was validated according to published guidelines. Positive and negative quality controls were prepared and their acceptance limits with $99 \%$ confidence were established to monitor the acceptability of the ELISA. As Saccharomyces cerevisiae is common yeast found in various foods, ASCA can appear in healthy persons and is very difficult to find a serum without ASCA as negative control. As novelty for this work is the use of a negative control, prepared with a pool of sera diluted with blocking buffer at MRD and preincubated with $100 \mu \mathrm{g} / \mathrm{mL}$ of the antigen used for plate coating. Since some discrepancies are marked when assessing specificity for ligand binding assays, the specificity was proved by a method of background noise suppression, reaching $100 \%$ of inhibition as strong criterion that supports the specificity of the immunoassay. The validation revealed that this ELISA is precise and robust to changes in incubation times and in substrate concentration. The stability of quality controls at short-term temperature and in freeze-thaw cycles was demonstrated, and it reflected the stability of the samples, since the quality controls and samples are of the same species. The validated ELISA is a reliable tool for ASCA detection in human serum after the administration of Heberprot-P ${ }^{\circledR}$, in order to find immunological reactions associated with latent contamination by host cell proteins from Saccharomyces cerevisiae.

\section{Acknowledgments}

None.

\section{Conflicts of interest}

The authors declare that they have no potential conflict of interests.

\section{Funding details}

The Center for Genetic Engineering and Biotechnology (CIGB) is a Cuban institution of a dynamic development which has reached a high level of research and development of biopharmaceuticals (www. cigb.edu.cu).

\section{References}

1. Hong KK, Nielsen J. Metabolic engineering of Saccharomyces cerevisiae: a key cell factory platform for future biorefineries. Cell. Mol. Life Sci. 2012;69(16):2671-2690.

2. Jonikas MC, Collins SR, Denic V, et al. Comprehensive characterization of genes required for protein folding in the endoplasmic reticulum. Science. 2009;323(5922):1693-1697.

3. Ilmen M, den Haan R, Brevnova E, et al. High level secretion of cellobiohydrolases by Saccharomyces cerevisiae. Biotechnol Biofuels. 2011;4:30.

4. Huang M, Bao J, Nielsen J. Biopharmaceutical protein production by Saccharomyces cerevisiae. Pharm Bioprocess. 2014;2:167-182.

5. United States Pharmacopeia. USP 39 Published General Chapter $<1132>$ Residual Host Cell Protein Measurement in Biopharmaceuticals. The United States Pharmacopeial Convention 12601 Twinbrook Parkway, Rockville, USA, 2016. p. 1-23.

6. Huang L, Zhang J, Qiao Q, et al. Clinical significance of antiSaccharomyces cerevisiae antibody in Crohn's disease: a single-center study. Int J Clin Exp Pathol. 2016;9(7):11978-11983.

7. Wang ZZ, Shi KE, Peng J. Serologic testing of a panel of five antibodies in inflammatory bowel diseases: Diagnostic value and correlation with disease phenotype. Biomed Rep. 2017;6:401-10.

8. Enzyme immunoassay for the determination of $\operatorname{Ig} G$ antibodies to Saccharomyces cerevisiae in human serum. The Eagle Biosciences ASCA IgG ELISA Assay Kit Catalog Number: ASG31-K01. 20A Northwest Blvd., Suite 112, Nashua, NH 03060. 1999.

9. Assay Development and Validation for Immunogenicity Testing of Therapeutic Protein Products. Guidance for Industry. U.S. Department of Health and Human Services Food and Drug Administration. Pharmaceutical Quality/CMC. Revision 1. 2016.

10. Immunogenicity Testing of Therapeutic Protein Products -Developing and Validating Assays for Anti-Drug Antibody Detection. Guidance for Industry. U.S. Department of Health and Human Services. Food and Drug Administration. Pharmaceutical Quality/CMC. 2019. p. 1-37.

11. EMA. Guideline on Bioanalytical Method Validation. European Medicines Agency, London, UK. 2011. p. 1-23.

12. Mire-Sluis AR, Barrett Y, Devanarayan V, et al. Recommendations for the design and optimization of immunoassays used in the detection of host antibodies against biotechnology products. J Immunol Methods. 2004;289(1-2):1-16.

13. Huber, L. Validation and Qualification in Analytical Laboratories. Interpharm, Informa Healthcare, New York, USA, 2007.

14. Kazaa M, Karazniewicz-Ładab M, Kosickab K, et al. Bioanalytical method validation: new FDA guidance vs. EMA guideline. Better or worse? J Pharm Biomed Anal. 2019;165:381-385.

15. Shankar G, Devanarayan V, Amaravadi L, et al. Recommendations for the validation of immunoassays used for detection of host antibodies against biotechnology products. J Pharm Biomed Anal. 2008;48(5):1267-1281.

16. Miller AM, Rutkowska A, Bahl JM, et al. Multicenter immunoassay validation of cerebrospinal fluid neurofilament light: a biomarker for neurodegeneration. Bioanalysis. 2016;8(21):2243-2254. 